УДК 614.833.4

ПОВЫШЕНИЕ ЭНЕРГЕТИЧЕСКОЙ И ЭКОЛОГИЧЕСКОЙ ЭФФЕКТИВНОСТИ АБСОРБЦИОННОЙ ОСУШКИ ПРИРОДНОГО ГАЗА

\title{
INCREASE IN ENERGY AND ENVIRONMENTAL EFFICIENCY OF ABSORBING DRYING NATURAL GAS
}

\author{
С.А. Шевцов, Д.В. Каргашилов, Е.Ю. Лазурко
}

Воронежский институт - филиал Ивановской пожарно-спасательной академии ГПС МЧС России, г. Воронеж, Российская Федерация

$$
\text { Д.А. Белов }
$$

Ивановская пожарно-спасательная академия ГПС МЧС России, г. Иваново, Российская Федерация

Sergey A. Shevtsov, DmitriyV. Kargashilov, Evgeniy Yu. Lazurko

The Voronezh institute - branch of the Ivanovo rescue and fire fighting academy of the public fire service Emercom of Russia, Voronezh, Russian Federation

\section{D.A. Belov}

The Ivanovo rescue and fire fighting academy of the public fire service Emercom of Russia, Ivanovo, Russian Federation

$$
\text { e-mail: shevtsov_sa@vigps.ru }
$$

Аннотация. В статье предложена энергоэффективная и экологически чистая в сочетании с пониженной пожарной опасностью технология абсорбционной осушки природного газа диэтиленгликолем, которая предусматривает противоточное движение газа и раствора диэтиленгликоля в трехсекционном абсорбере; очистку газа от взвешенных капель жидкости в 
нижней скрубберной секции, поглощение паров воды диэтиленгликолем при движении газа через систему тарелок в средней секции, и последующую очистку газа от захваченных капель раствора диэтиленгликоля в верхней скрубберной секции; вывод осушенного газа из абсорбера с доставкой потребителю; регенерацию использованного раствора диэтиленгликоля в десорбере, состоящего из верхней части тарельчатого типа, в которой из раствора диэтиленгликоля, стекающего вниз, выпаривается влага встречным потоком острого водяного пара и паров диэтиленгликоля, и нижней части, где происходит нагревание раствора с помощью кипятильника до температуры $150-160^{\circ} \mathrm{C}$ и испарение воды; конденсацию водяного пара, отводимого из десорбера, в конденсаторе-холодильнике с подачей полученной воды в верхнюю часть десорбера; отвод регенерированного горячего раствора диэтиленгликоля из нижней части десорбера, его подачу на осушение газа в абсорбер с максимальной рекуперацией теплоты на нагрев насыщенного раствора диэтиленгликоля, подаваемого на регенерацию в теплообменники и холодильник.

Для подготовки теплоносителя («холодной» и «горячей» воды) используется пароэжекторный тепловой насос, состоящий из эжектора, испарителя, холодоприемника, конденсатора, терморегулирующего вентиля, парогенератора с предохранительным клапаном, насоса рециркуляции хладагента через холодоприемник, работающих по замкнутому термодинамическому циклу; причем одна часть полученного в парогенераторе острого пара направляется в кипятильник десорбера с возвратом образовавшегося конденсата в парогенератор, а другая часть в качестве рабочего пара под давлением 0,05-0,06 МПа направляется в сопло эжектора, вовлекая эжектируемые пары хладагента в качестве которого используется вода из испарителя и создается в нем пониженное давление 0,0009-0,001 МПа с температурой кипения хладагента 4-7 ${ }^{\circ} \mathrm{C}$; за счет рецируляции хладагента через холодоприемник получается «холодная» вода с температурой 7-10 ${ }^{\circ} \mathrm{C}$ путем рекуперативного теплообмена между хладагентом и «холодной» водой, один поток которой подается в конденсатор-холодильник 
для конденсации водяного пара, отводимого из десорбера, а второй в холодильник; образовавшаяся после эжектора смесь паров хладагента и рабочего пара направляется в конденсатор пароэжекторного теплового насоса, а теплота конденсации смеси паров хладагента и рабочего пара используется для получения «горячей» воды, которая посредством рекуперативного теплообмена нагревается до температуры $40-50{ }^{\circ} \mathrm{C}$ и подается на подогрев газа перед абсорбером до температуры $30-40^{\circ} \mathrm{C}$ с возвратом в конденсатор пароэжекторного теплового насоса; причем одна часть образовавшегося в конденсаторе водяного конденсата подается через терморегулирующий вентиль в испаритель для пополнения убыли воды, а другая избыточная часть конденсата вместе с отработанной водой после конденсатора-холодильника и холодильника отводится в парогенератор с образованием замкнутого цикла.

Abstract. The article proposes an energy-efficient and environmentally friendly technology, combined with a reduced fire hazard, the technology of absorption dehydration of natural gas with diethylene glycol, which provides for the counter-movement of gas and diethylene glycol solution in a three-section absorber; gas purification from suspended liquid droplets in the lower scrubber section, absorption of water vapor by diethylene glycol during gas movement through a system of plates in the middle section, and the subsequent gas cleaning from trapped drops of diethylene glycol solution in the upper scrub bern section; the output of the dried gas from the absorber c delivery to the consumer; regeneration of the used solution of diethyleneglycol in the desorber, consisting of the upper part of the plate type, in which the moisture from the diethyleneglycol solution flowing downwards is evaporated by a counter stream of acute water vapor and diethyleneglycol vapor, and the lower part, where the solution is heated using a boiler to a temperature of $150-160^{\circ} \mathrm{C}$ and the evaporation of water; condensation of water vapor discharged from the stripper in the condenser-cooler with the supply of the produced water to the upper part of the stripper; from the water of the regenerated hot diethylene glycol solution from the bottom of the stripper, its supply for drying the gas to the absorber with max- 
imum heat recuperation to heat the saturated diethylene glycol solution fed to the regeneration in the heat exchangers and the refrigerator.

To prepare the heat carrier («cold» and «hot» water), a steam ejector heat pump is used, consisting of an ejector, an evaporator, a cold receiver, a condenser, a thermostatic valve, a steam generator with a safety valve, a recirculation pump - refrigerant sections through a cold receiver, operating in a closed thermo-dynamic cycle; moreover, one part of the steam produced in the steam generator is sent to the desorber boiler with return of the condensate formed to the steam generatorgenerator, and the other part as working steam under pressure of $0.05-0.06 \mathrm{MPa}$ is sent to the ejector nozzle, involving refrigerant vapors, in which water from the evaporator is used, and a lower pressure of $0.0009-0.001 \mathrm{MPa}$ is created in it with a boiling point of refrigerant $4-7^{\circ} \mathrm{C}$; due to the reclamation of the refrigerant through the cold receiver, it produces «cold» water with a temperature of $7-10{ }^{\circ} \mathrm{C}$ by recuperative heat exchange between the refrigerant and the «cold» water, one stream of which is fed to the condenser / cooler for condensation of water vapor discharged from the stripper, and the second in a refrigerator; The mixture of refrigerant vapor and working steam formed after the ejector is sent to the steam ejector heat pump condenser, and the heat of condensation of the refrigerant vapor mixture and the operating steam is used to produce «hot» water, which is heated to $40-50{ }^{\circ} \mathrm{C}$ and fed to the heated gas in front of the absorber to a temperature of $30-40{ }^{\circ} \mathrm{C}$ with return to the steam ejector heat pump condenser; moreover, one part of water condensate formed in the condenser is fed through the thermostatic valve to the evaporator to replenish water loss, and the other excess part of the condensate, together with the waste water after the condenser-cooler and refrigerator, is discharged into the steam generator to form a closed cycle.

Ключевые слова: энергоэффективность, экологическая безопасность, пожарная опасность, природный газ, абсорбционная осушка, тепловой насос, диэтиленгликоль

Key words: energy efficiency, ecological safety, fire danger, natural gas, absorbing drying, thermal pump, diethylene glycol 
Мировые потребности в углеводородном газе продолжают неуклонно увеличиваться по мере роста и развития техники и технологий, экономик и населения различных стран [1].

Российская Федерация занимает лидирующее положение в поставках больших объемов природного газа на мировой рынок, что имеет стратегическое значение для обеспечения экономической и энергетической безопасности государства.

В условиях мировой конкуренции бесперебойный трубопроводный транзит и развитие высокоточных промышленных и бытовых газовых приборов предъявляют к качеству природного газа высокие эксплуатационные требования, в частности к его влажности [2].

Осушка природного газа требует больших затрат энергии, что при увеличении роста потребности является важнейшим экономическим фактором. Кроме того, современные технологии осушки природного газа характеризуются высокой степенью пожарной опасности, что обусловлено применением большого количества легковоспламеняющихся и горючих веществ, находящихся в разнообразных технологических аппаратах и связанных в единую технологическую цепь. В разветвленной сети трубопроводов с многочисленными фланцевыми соединениями и арматурой возможно нарушение герметичности, что может сопровождаться утечкой продукта с образованием взрывоопасных смесей. Развитие подобного сценария создает реальную угрозу возникновения крупной техногенной катастрофы, сопряженной с пагубным экологическим воздействием на окружающую среду [3].

Задача сокращения энергетических затрат в сочетании со снижением пожарной опасности в технологическом процессе осушки природного газа в условиях чистой экологии является актуальной научной проблемой.

Для ее решения предлагается совершенствование технологии абсорбционной осушки природного газа диэтиленгликолем за счет применения эффективных теплонасосных технологий, позволяющих сократить затраты 
на выработку энергии при наиболее рациональных с энергетической точки зрения схемах подключения теплового насоса. При этом основой энергоэффективности является применение возобновляемых источников энергии, а основой снижения пожарной опасности - исключение из процесса взрыво- и пожароопасных рабочих сред. Основными преимуществами применения теплового насоса являются его высокая энергоэффективность, безопасность и надежность [4].

Технологическая схема, реализующая предлагаемую технологию абсорбционной осушки природного газа диэтиленгликолем, представлена на рисунке 1 [5].

Газ, требующий осушки, предварительно нагревается до $30-40{ }^{\circ} \mathrm{C}$ в теплообменнике 21 посредством рекуперативного теплообмена с «горячей» водой и по линии 0.10 подается в трехсекционный абсорбер 1, в котором при противоточном движении газа и раствора диэтиленгликоля сначала в нижней скрубберной секции освобождается от взвешенных капель жидкости; затем в средней секции диэтиленгликоль поглощает пары воды из газа при его движении чрез систему тарелок и далее в верхней скрубберной секции осуществляется окончательная очистка газа, в том числе и от захваченных капель раствора диэтиленгликоля с последующим выводом осушенного газа из абсорбера по линии 0.11 с доставкой потребителю.

Насыщенный раствор диэтиленгликоля с влажностью 2,0-2,5 \% отбирается с нижней глухой тарелки абсорбера 1 , подогревается в теплообменнике 3 встречным потоком регенерированного раствора и по линии 2.0 направляется в выветриватель 5, через который выводятся неконденсирующиеся газы по линии 2.2. Далее раствор подогревается в теплообменнике 4 и подается в десорбер 2. 


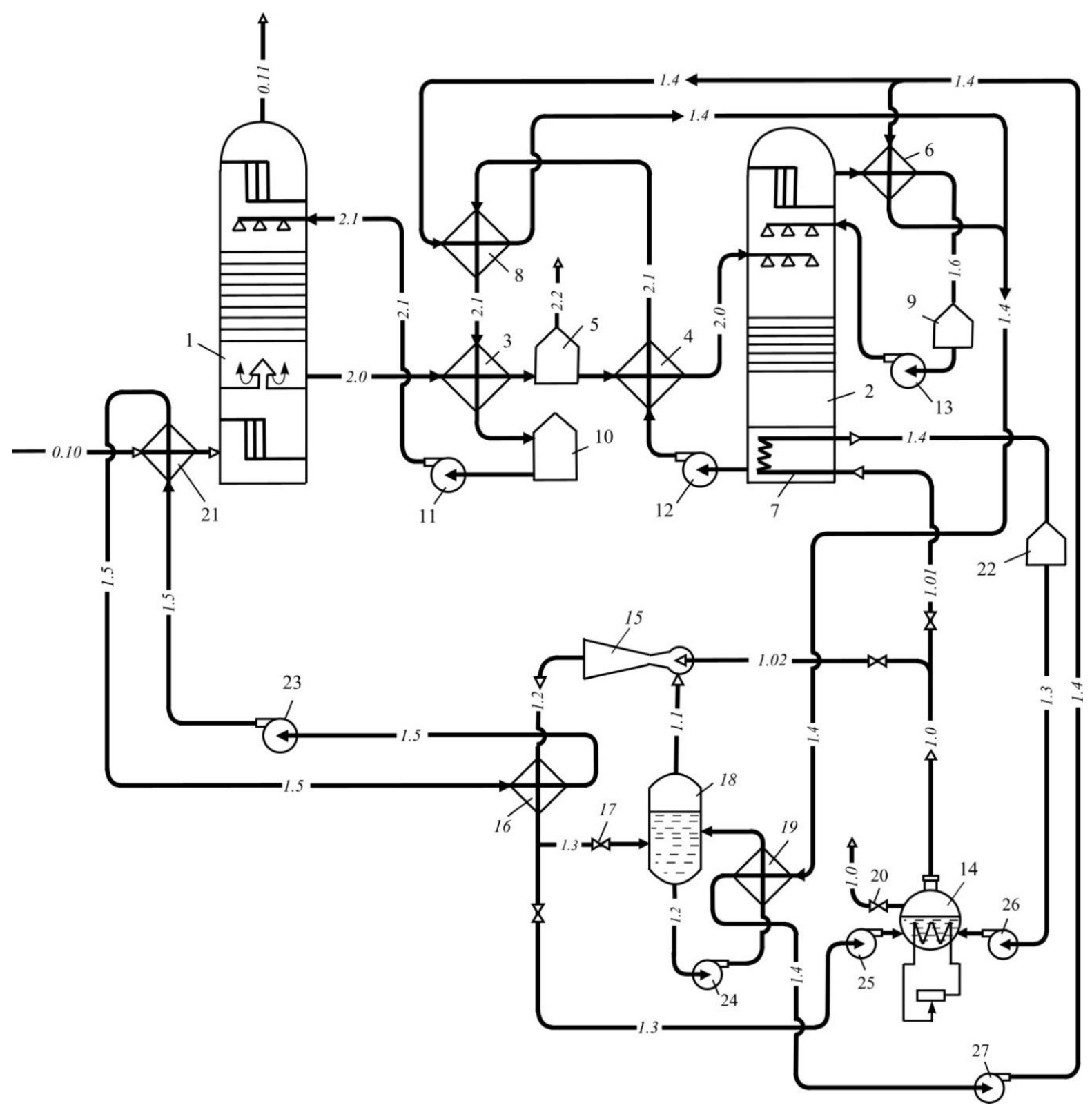

1 - абсорбер; 2 - десорбер; 3, 4, 21 - теплообменники; 5 - выветриватель; 6 - конденсатор-холодильник; 7 - кипятильник; 8 - холодильник; 9, 10, 22 - емкости; 11, 12, 13, 23, 24, 25, 26, 27 - насосы; 14 - парогенератор; 15 - эжектор; 16 - конденсатор; 17 - терморегулирующий вентиль; 18 - испаритель; 19 - холодоприемник; 20 - предохранительный клапан;

линии подачи: 0.10 - влажный газ; 0.11 - осушенный газ; 2.0 - насыщенный раствор этиленгликоля;

2.1 - регенерированный раствор этиленгликоля; 2.2 - несконденсировавшиеся газы; 1.0 - перегретый пар; 1.01 - острый пар; 1.02 - рабочий пар; 1.1 - эжектируемый пар; 1.2 - смесь паров хладагента и рабочего пара; 1.3 - конденсат; 1.4 - холодная вода; 1.5 - горячая вода; 1.6 - смесь паров воды и этиленгликоля

Рисунок 1. Технологическая схема абсорбционной осушки природного газа диэтиленгликолем с применением пароэжекторной холодильной машины 
Десорбер 2 состоит из двух частей: собственно колонны тарельчатого типа, в которой из раствора диэтиленгликоля, стекающего вниз, выпаривается влага встречным потоком острого водяного пара и паров диэтиленгликоля (верхняя основная часть колонны) и кипятильника (нижняя часть колонны), где нагревается раствор до температуры 150-160 $\mathrm{C}$, создавая условия для испарения воды.

Водяной пар из десорбера отводится в конденсатор-холодильник 6 , где он конденсируется и собирается в емкость 9. Часть полученной воды насосом 13 закачивается в верхнюю часть колонны по линии 1.6, чтобы несколько снизить там температуру и уменьшить испарение, а, соответственно, и унос диэтиленгликоля.

Работа десорбера основана на различной температуре кипения воды и абсорбента: для диэтиленгликоля она равна $244,5^{\circ} \mathrm{C}$.

Регенерированный горячий раствор диэтиленгликоля прокачивается в емкость 10 насосом 12 по линии 2.1 последовательно через теплообменник 4, холодильник 8 и теплообменник 3.

В конденсатор-холодильник 6 и холодильник 8 по линиям 1.4 насосом 27 подается «холодная» вода температурой $10-12{ }^{\circ} \mathrm{C}$ соответственно для конденсации паров воды из диэтиленгликоля в контуре рециркуляции 1.6 и для снижения температуры регенерированного горячего раствора диэтиленгликоля в линии 2.1 перед теплообменником 3. Отработанная «холодная» вода после конденсатора-холодильника 6 и холодильника 8 возвращается по линии 1.4 в холодоприемник 19 и с помощью насоса 27 осуществляется ее рециркуляция.

Для подготовки «холодной» и «горячей» воды используется пароэжекторная холодильная машина, работающая в режиме теплового насоса, coстоящая из эжектора 15 , испарителя 18 , холодоприемника 19 , конденсатора 16, терморегулирующего вентиля 17, парогенератора 14 с предохранительным клапаном 20, насоса 24 рециркуляции хладагента через холодоприемник, работающих по замкнутому термодинамическому циклу. 
Одна часть полученного в парогенераторе острого пара по линии 1.01 направляется в кипятильник 7 десорбера 2 с возвратом образовавшегося конденсата в парогенератор по линии 1.4 через емкость 22, а другая часть в качестве рабочего пара под давлением 0,05-0,06 МПа направляется по линии 1.02 в сопло эжектора 15, вовлекая по линии 1.1 эжектируемые пары хладагента, в качестве которого используется воду, из испарителя 18 и создают в нем пониженное давление 0,0009...0,001 МПа с температурой кипения хладагента $4 . .7{ }^{\circ} \mathrm{C}$. За счет рецируляции хладагента через холодоприемник по контуру 1.2 получается «холодная» вода с температурой 7...10 ${ }^{\circ} \mathrm{C}$ путем рекуперативного теплообмена между хладагентом и «холодной» водой.

Образовавшаяся после эжектора 15 смесь паров хладагента и рабочего пара по линии 1.2 направляется в конденсатор 16 пароэжекторного теплового насоса, а теплота конденсации смеси паров хладагента и рабочего пара используется для получения «горячей» воды, которая посредством рекуперативного теплообмена нагревается до температуры $40-50{ }^{\circ} \mathrm{C}$ и по линии 1.5 подается в теплообменник 21 на подогрев газа перед абсорбером до температуры $30-40{ }^{\circ} \mathrm{C}$ с возвратом в конденсатор 16 пароэжекторного теплового насоса.

Одна часть образовавшегося в конденсаторе 16 водяного конденсата по линии 1.3 подается через терморегулирующий вентиль 17 в испаритель 18 для пополнения убыли воды, а другая избыточная часть с помощью насоса 25 вместе с конденсатом, образовавшимся после кипятильника 7, из емкости 22 с помощью насоса 26 отводится в парогенератор 14 с образованием замкнутого цикла.

При увеличении давления пара в парогенераторе 14 срабатывает предохранительный клапан 20, осуществляющий сброс давления по линии 1.0.

Предлагаемая технология осушки газа диэтиленгликолем с применением пароэжекторного теплового насоса расширяет границы энергоэффективного сопряжения объектов различных температурных потенциалов на 
основе утилизации и рекуперации вторичных энергоресурсов. При этом в полной мере реализован универсальный подход в создании энергосберегающей и экологически- и взрывопожаробезопасной технологии, обеспечивающей выработку тепла и холода для совместно протекающих процессов абсорбционной осушки углеводородного газа от влаги раствором диэтиленгликоля и десорбции при регенерации насыщенного влагой раствора диэтиленгликоля.

\section{Вывод}

Таким образом, предлагаемая технология имеет следующие преимущества по сравнению с аналогами:

- позволяет снизить удельные энергозатраты на 5-7 \% при осушке газа диэтиленгликолем за счет рационального подключения к схеме энергоснабжения смежных процессов пароэжекторного теплового насоса;

- создает экологически и взрывопожаробезопасные условия реализации способа за счет применения воды в качестве хладагента, исключая использование токсичных, взрыво- и пожароопасных рабочих сред, а также за счет организации замкнутых рециркуляционных схем по материальным и энергетическим потокам со значительным снижением отвода вторичных энергоресурсов из схемы тепло- и холодоснабжения;

- в качестве энергоносителя используется водяной пар с давлением 0,05-0,06 МПа, благодаря чему достигается экономия электроэнергии, которая расходуется только на работу насосов и теплонагревательных элементов парогенератора.

\section{Список используемых источников}

1. Holditch S.A., Chianelli R.R. Factors That Will Influence Oil and Gas Supply and Demand in the 21st Century // MRS Bulletin. 2008. № 33(4). P. 317-323. DOI: 10.1142/7863. 
2. Кондауров С.Ю. Совершенствование технологии адсорбционной осушки и отбензинивания природного газа: дис. ... канд. техн. наук. Спб: Изд-во Газпром ВНИИГАЗ, 2012. 141 с.

3. Shevtsov S.A., Kargashilov D.V., Shutkin A.N. Fire and Explosion Safe Technology of Storage and Regasification of Liquefied Petroleum Gas // Chemical and Petroleum Engineering. 2018. P. 1-3.

4. Лунева С.К. Решение вопросов энергосбережения и энергоэффективности при применении тепловых насосов // Техникотехнологические проблемы сервиса. 2014. № 3 (29). С. 59-62.

5. Патент 2634782 Российская Федерация, МПК В 01 D 53/26, В 01 D 53/14, В 01 D 3/00. Способ осушки углеводородного газа диэтиленгликолем / Шевцов С.А., Калач А.В., Каргашилов Д.В., Сапелкин Д.И. № 2016129908; заявл. 20.07.2016; опубл. 03.11.2017, Бюл. № 31 .

\section{References}

1. Holditch S.A., Chianelli R.R. Factors That Will Influence Oil and Gas Supply and Demand in the 21st Century. MRS Bulletin, 2008, № 33(4), pp. 317-323. DOI: 10.1142/7863.

2. Kondaurov S.Yu. Sovershenstvovanie tekhnologii adsorbtsionnoi osushki $i$ otbenzinivaniya prirodnogo gaza: dis. kand. tehn. nauk. [Improving the Technology of Adsorption Drying and Natural Gas Topping: diss. ... Cand. Engin. Sci.]. Saint-Petersburg, Gazprom VNIIGAZ Publ., 2012. 141 p. [in Russian].

3. Shevtsov S.A., Kargashilov D.V., Shutkin A.N. Fire and Explosion Safe Technology of Storage and Regasification of Liquefied Petroleum Gas. Chemical and Petroleum Engineering, 2018, pp. 1-3.

4. Luneva, S.K. Reshenie voprosov ehnergosberezheniya i ehnergoehffektivnosti pri primenenii teplovyh nasosov [The Solution of Questions of Energy Saving and Energy Efficiency at Use of Thermal Pumps]. Tekhniko-tekhnologicheskie problemy servisa-Technical and Technological Problems of Service, 2014. № 3 (29), pp. 59-62. [in Russian]. 
5. Shevtsov S.A., Kalatch A.V., Kargashilov D.V., Sapelkin D.I. Sposob osushki uglevodorodnogo gaza diehtilenkligolem [Way of Drying of Hydrocarbonic Gas Diethylene Glycol]. Patent RF, No. 2634782, 2017. [in Russian].

\section{Сведения об авторах}

\section{About the authors}

Шевцов Сергей Александрович, д.т.н., профессор кафедры пожарной безопасности объектов защиты, Воронежский институт - филиал Ивановской пожарно-спасательной академии ГПС МЧС России, г. Воронеж, Российская Федерация

Sergey A. Shevtsov, Doctor of Engineering Sciences, Professor of Defense Objects Fire Safety Department, The Voronezh Institute - Branch of the Ivanovo Rescue and Fire Fighting Academy of the Public Fire Service Emercom of Russia, Voronezh, Russian Federation

e-mail: shevtsov_sa@vigps.ru

Каргашилов Дмитрий Валентинович, канд. техн. наук, доцент, заместитель начальника института (по учебной работе), Воронежский институт филиал Ивановской пожарно-спасательной академии ГПС МЧС России, г. Воронеж, Российская Федерация

Dmitriy V. Kargashilov, Candidate of Engineering Sciences, Associated Professor, Deputy Head of Institute (on Scientific Work), The Voronezh Institute - Branch of the Ivanovo Rescue and Fire Fighting Academy of the Public Fire Service Emercom of Russia, Voronezh, Russian Federation 
Лазурко Евгений Юрьевич, курсант пятого курса факультета инженеров пожарной безопасности, Воронежский институт - филиал Ивановской пожарно-спасательной академии ГПС МЧС России, г. Воронеж, Российская Федерация

Evgeniy Yu. Lazurko, Fifth Class Student of Fire Safety Engineers Department, The Voronezh Institute - Branch of the Ivanovo Rescue and Fire Fighting Academy of the Public Fire Service Emercom of Russia, Voronezh, Russian Federation

Белов Дмитрий Александрович, студент магистратуры по направлению «Техносферная безопасность», Ивановская пожарно-спасательная академия ГПС МЧС России, г. Иваново, Российская Федерация

Dmitriy A. Belov, Under-Graduate Student of the Program «Technosphere Safety», The Ivanovo Rescue and Fire Fighting Academy of the Public Fire Service Emercom of Russia, Ivanovo, Russian Federation 